\title{
Skateboarding injuries of today
}

\author{
L Forsman, A Eriksson
}

\begin{abstract}
Background-Skateboarding injuries have increased with the rise in popularity of the sport, and the injury pattern can be expected to have changed with the development of both skateboard tricks and the materials used for skateboard construction.
\end{abstract}

Objective-To describe the injury pattern of today.

Methods-The pattern of injuries, circumstances, and severity were investigated in a study of all 139 people injured in skateboarding accidents during the period 1995-1998 inclusive and admitted to the University Hospital of Umeå. This is the only hospital in the area, serving a population of 135000 .

Results-Three of the 139 injured were pedestrians hit by a skateboard rider; the rest were riders. The age range was $7-47$ years (mean 16). The severity of the injuries was minor (AIS 1) to moderate (AIS 2); fractures were classified as moderate. The annual number of injuries increased during the study period. Fractures were found in $29 \%$ of the casualties, and four children had concussion. The most common fractures were of the ankle and wrist. Older patients had less severe injuries, mainly sprains and soft tissue injuries. Most children were injured while skateboarding on ramps and at arenas; only $12(9 \%)$ were injured while skateboarding on roads. Some $37 \%$ of the injuries occurred because of a loss of balance, and $26 \%$ because of a failed trick attempt. Falls caused by surface irregularities resulted in the highest proportion of the moderate injuries.

Conclusions-Skateboarding should be restricted to supervised skateboard parks, and skateboarders should be required to wear protective gear. These measures would reduce the number of skateboarders injured in motor vehicle collisions, reduce the personal injuries among skateboarders, and reduce the number of pedestrians injured in collisions with skateboarders.

(Br F Sports Med 2001;35:325-328)

Keywords: skateboard; injury; prevention

In the 1960s, skateboarding became popular among young people in the United States, but the first real skateboard craze occurred in the 1970 s with the introduction of the polyurethane wheel and other improvements that made skateboards more manoeuvrable. This development was, not surprisingly, accompanied by a surge in the number of skateboard related injuries. ${ }^{1-7}$ There were calls for restrictions that would reduce these injuries, ${ }^{8}$ and in Sweden, skateboarding was banned from public roads and sidewalks in many communities in 1980. Furthermore, legislation was passed that required all skateboard buyers to be at least 12 years old and all skateboards sold to be labelled with a warning notice about the hazards. Other countries chose an even stricter approach: in Norway, skateboarding was banned. This resulted in decreased popularity during the 1980s. In the 1990s, skateboarding bans were, however, repealed throughout Sweden, and skateboarding again increased in popularity.

As with many sports that involve speed and balance, skateboarding can result in injury. Indeed, when first introduced in the 1960 s, skateboarding was referred to as a "new medical menace", 9 and, since then, the sport has caused many injuries, sometimes resulting in deformity and morbidity. ${ }^{6}{ }^{10}$ Although most studies report a high occurrence of minor injuries, more serious ones have also been reported, ${ }^{10} 11$ especially from skateboarding on roads, which can lead to collisions with cars which may even result in fatality. ${ }^{11}{ }^{12}$ Contributing to the danger is the high speeds, 60-90 $\mathrm{km} / \mathrm{h}$, that can be reached with today's boards, ${ }^{13-15}$ and the absence of a mechanical braking system.

Skateboarding has been around for more than four decades, but most of the literature on skateboard injuries was published in the 1970s, with a second peak in the early 1990s. As the sport has developed, the types of injury can be expected to have changed. The purpose of the this study was to describe patterns of injuries and accidents among skateboarders today to provide a basis for preventive measures.

\section{Materials and methods}

At the University Hospital of Umeå all patients seeking emergency health care because of an injury are asked to complete a questionnaire that asks them when, where, and under what circumstances their injury took place. Details about the nature, diagnosis, and treatment of the injuries and their sequelae were obtained from the patients' medical records. This registration protocol has been in place since 1985 and is now part of the European cooperation project EHLASS (European Home and Leisure Accident Surveillance System). This system focuses on collecting information about the cause of injuries and the injury events. No information was obtained about the skateboarders' level of expertise or use of protective gear. From this information, a descriptive 


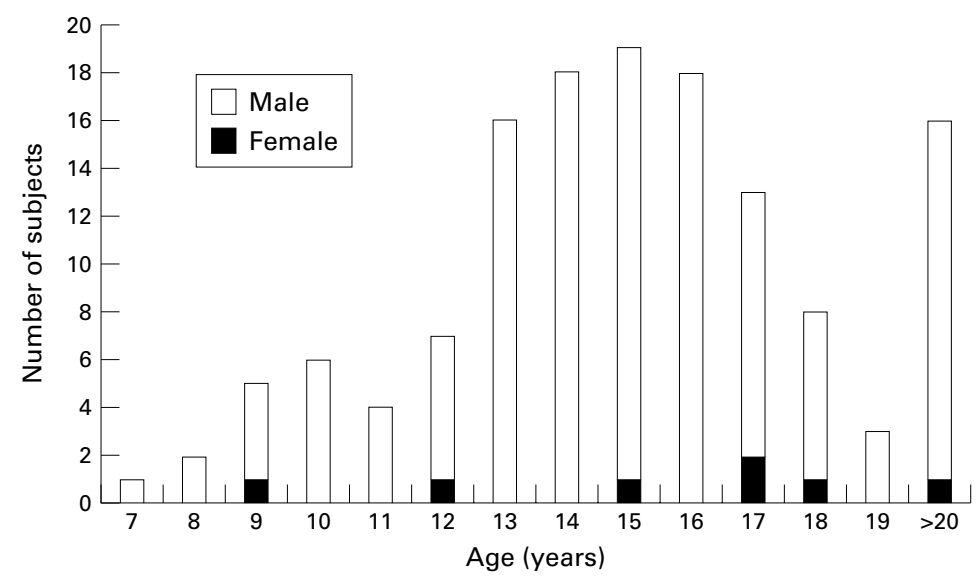

Figure 1 Age and sex distribution of 136 injured skateboarders.

analysis of all skateboard injuries recorded in 1995-1998 inclusive was undertaken. The

\begin{tabular}{ll}
$\begin{array}{l}\text { Table } 1 \text { Distribution of } \\
\text { fractures in skateboarders }\end{array}$ \\
\hline Site of fracture & No \\
\hline Upper extremity & 24 \\
Clavicle & 4 \\
Shoulder & 1 \\
Humerus & 1 \\
Elbow & 2 \\
Wrist & 8 \\
Hand & 5 \\
Finger & 3 \\
Lower extremity & 18 \\
Tibia & 1 \\
Ankle & 8 \\
Metatarsal & 7 \\
Toe & 2 \\
Total & 42 \\
\hline
\end{tabular}
hospital is the only one in the area, and serves a population of 135000 .

The severity of the injuries was assessed according to the Abbreviated Injury Scale (AIS). ${ }^{16}$ Lacerations, contusions, bruises, and cuts are classified as AIS 1, most noncomplicated fractures as AIS 2, and more serious injuries up to AIS 6.

\section{Results}

During the study period, 139 people with skateboard related injuries were treated. Three of these were pedestrians injured by a collision with a skateboard rider. Two were young boys, 4 and 5 years old, who suffered minor injuries such as skin lacerations and contusions. The third was a 71 year old woman, who was admitted to hospital with a fracture of the femoral neck (AIS 3). The following results describe the injuries of skateboarders only.

The study thus included 136 skateboarders, $95 \%$ of whom were male. The age distribution ranged from 7 to 47 years, with more than half of the patients being between 13 and 16 years (fig 1). The mean age was 16 . The casualties were divided into four age groups: $0-9,10-14$, 15-19, and 20 and over.

TYPES OF INJURY

Of the 147 injuries recorded, the most common were sprains $(44 \%)$ and fractures (29\%) (fig 2). Soft tissue injuries, including

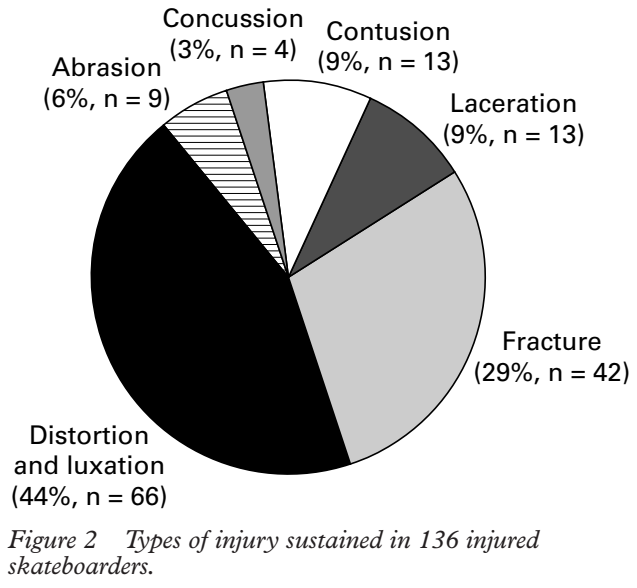

abrasions, contusions, and lacerations, accounted for $24 \%$. Four cases of concussion and four joint dislocations were recorded. The largest proportion of fractures $(56 \%)$ occurred in the youngest age group. Only two fractures were found among those 20 years or older; sprains were the most common injury in this age group.

\section{BODY PART INJURED}

The largest proportion of the injuries affected the lower extremity (50\%), whereas fractures were more common in the upper extremity $(57 \%, \mathrm{n}=24)$. Of the fractures of the hand, two were scaphoid fractures. Fractures in the lower extremity were most commonly seen in the ankle or the foot (table 1).

\section{SEVERITY OF INJURY}

Most of the injuries $(70 \%)$ were classified as AIS 1 (minor), the remainder being classified as AIS 2 (moderate). None was regarded as "serious" (AIS 3 or more). The moderate injuries included various simple fractures, two knee sprains, and four cases of concussion. The severity of the injuries decreased with age, and three of the four head injuries occurred in the youngest age groups.

\section{INJURY MECHANISM}

Nine injury events occurred when the skateboard struck irregularities in the riding surface, whereas most patients (49) cited more unspecific causes such as loss of balance or "just fell off" as the mechanism of the injury. Thirty eight patients reported the cause of injury as a loss of control when attempting a jump or a trick, and five were hit by an airborne skateboard. Eight patients reported a "sudden movement" and another eight their "foot getting stuck between the skateboard and the riding surface" as the mechanism of injury. One patient was injured while holding on to a moving car to increase the speed. No injuries involved any board failure or collisions with motor vehicles (table 2 ). In the two youngest age groups, loss of balance was the most common mechanism of injury; the older adolescents mostly lost control during jumps and tricks. Hitting surface irregularities caused the highest proportion of AIS 2 injuries $(56 \%, \mathrm{n}=$ 5). Failing a jump or trick resulted in AIS 1 injuries in most cases.

\section{LOCATION OF INJURY EVENT}

Most of the injury events $(24 \%, \mathrm{n}=33)$ took place at specially designed areas, parks, and ramps for skateboarding. Thirteen occurred in school yards, 12 in public roads within densely populated residence areas, and the rest at miscellaneous places such as market places, court yards, parking areas, etc. A popular place for skateboarders was the Umea market place, where seven of the accidents occurred.

At skateboard ramps, $76 \%$ of the accidents resulted in minor injuries; at schoolyards, 54\% of the accidents were classified as AIS 2 . 
Table 2 Primary mechanism of skateboard injury as stated by the injured $(n=131)$

\begin{tabular}{ll}
\hline Primary mechanism of injury & No \\
\hline "Loss of balance" & 49 \\
Failure in performing a jump or trick & 34 \\
Sudden stop caused by irregularities in the riding surface & 9 \\
Foot stuck between the board and the riding surface & 8 \\
Acute straining of limbs caused by own movement & 8 \\
Hit by moving airborne board & 5 \\
Falling when riding on steps & 5 \\
Miscellaneous and non-specified & 13 \\
\hline
\end{tabular}

TREATMENT AND SEQUELAE

For most patients $(62 \%, \mathrm{n}=82)$ only the initial treatment without any additional appointments was required, but $15 \%(n=20)$ did require further appointments. Thirteen patients did not need any treatment at all and were sent home after the examination. Eleven patients were admitted to hospital for observation and further treatment for a total of 21 days. None of the accidents resulted in permanent injury or deformity.

\section{Discussion}

Skateboarding not only may result in injuries to the skateboarders themselves, but can also be a danger to pedestrians. This is illustrated by the elderly woman in our study who required eight follow up visits and who eventually developed pseudoarthrosis, necessitating the insertion of an artificial hip joint.

Of the injuries to the skateboarders, a surprisingly high proportion was located in the lower extremity. Nearly all previous studies have reported injuries affecting the upper extremity, such as wrist and hand fractures, to be the most prevalent. ${ }^{341317-21}$ An olecranon fracture, also called "skateboard elbow", ${ }^{11}$ was seen only in one case, and scaphoid fractures $^{22}{ }^{23}$ were also rare. Wrist fractures are a common outcome when the skateboard strikes surface irregularities and the skateboarder falls forwards and lands on outstretched arms. There are some possible explanations for the fact that the results of our study are not consistent with previous ones. For example, in our study, loss of balance and failure when attempting a jump or trick was a more common mechanism of injury, and the type of fall and resulting injury are therefore likely to differ. Depending on the trick attempted, the risk of landing askew seems to be higher than the risk of a skateboarder losing balance completely and falling on outstretched arms. Furthermore, new tricks are likely to change the pattern of injury. Also, our mean age of 16 is somewhat higher than the ages stated in other studies, which may have affected the pattern of injuries, because older skateboarders are likely to be more experienced and to attempt more tricks and jumps. Most patients older than 25 were using someone else's skateboard and were not regular skateboarders. Lastly, when considering the high proportion of fractures, it should be noted that EHLASS records only the most serious injury to a certain body part, meaning that minor soft tissue injuries are probably more common than shown in this study. In addition, skateboarding probably causes many trivial injuries not requiring medical attention.
Inexperience has been suggested by some authors to be a predisposing factor for injuries. ${ }^{824}$ However, as more experienced riders often attempt more difficult tricks and jumps, reach higher velocities, and exhibit more risky behaviour, the advantages of experience are counteracted. ${ }^{2}{ }^{7}$ Unlike for other recreational activities, an increase in age does not automatically mean fewer injuries. However, as confirmed by our results, the severity of the injuries decreases with age. $^{722526}$ Young people are often not fully mature with regard to balance, coordination, and estimation of speed, which predisposes them to more serious injuries. ${ }^{2727} 28$

Most skateboard injuries are minor, even trivial, but potentially life threatening injuries such as retroperitoneal haemorrhage, ${ }^{12}$ scrotoabdominal injury, ${ }^{24}$ and renal damage, ${ }^{5}$ have been reported, and fatalities have occurred. ${ }^{11}{ }^{12}$ Although none of the injuries in this study was considered severe, some of the fractures had the potential to cause deformity and growth retardation, such as fractures of the epiphyseal plate and the scaphoid. ${ }^{23}$

Severe and fatal skateboard accidents inevitably raise discussions about safety issues. When skateboarding injuries are compared with those from cycling ${ }^{21}$ or road accidents, ${ }^{22}$ which are generally more severe, the question of banning seems rather implausible. Although the skateboard injuries discussed here only represent $0.4 \%$ of the total number of injuries recorded at the hospital studied, the annual number more than doubled during the four year period of our study, from 23 in 1995 to 54 in 1998.

The efficacy of various preventive measures such as using protective gear, improving falling techniques, and enforcing age limits has been debated by many authors. ${ }^{3-5} 13-1518192228$ As this study did not gather information about the use of protective equipment at the time of the injury, we cannot comment on its value. The high incidence of fractured wrists and ankles, however, raises questions on how to avoid this particular type of injury. The use of padded ankle support ${ }^{1018}$ and sturdy footwear ${ }^{3}$ has been suggested, although others argue that the former is not feasible because freedom of movement of the ankle is important while skateboarding. Hand and wrist protection has also been suggested previously. ${ }^{23}$

The fatalities reported throughout the years mainly involved collisions with motor vehicles. ${ }^{722529}$ As skateboarding requires a hard smooth riding surface, it is not surprising that adolescents are attracted to public roads. Banning skateboarding from roads and highways has been unsuccessful, ${ }^{811}$ but a feasible alternative would be to provide safe areas for skateboarders, ${ }^{32}$ also reducing the risks for pedestrians. Interestingly, only a few people in our study group were injured on busy roads, whereas in studies from the United States up to one third of the injuries occurred in this setting. ${ }^{7}$ The discrepancy is probably explained by the fact that the city of Umeå has three skateboard arenas and ramps, not including home made ramps, reducing the use of 
skateboards on roads. The current trend of using the skateboard more for recreational purposes than as a means of transport may have contributed.

For most young people of today, skateboarding is not a means of transport but a lifestyle in which a whole industry of fashion and other accessories complements the sport. Home made ramps, skateboard associations, and professional and amateur competitions are other attributes of this lifestyle. Like other sports, skateboarding provides recreation and enjoyment for its participants and enthusiasts. It is thus the task of the community to contribute to increased safety by providing specially designed skateboard parks and developing individual protective gear.

1 Adams ID. Skateboard injuries. Nursing Times 1979;26:7078 .

2 Fountain JL, Meyers MC. Skateboarding injuries. Sports Med 1996;22:360-6.

3 Fyfe IS, Guion AJ. Accident prevention in skateboarding. $\mathcal{F}$ Sports Med 1979;19:265-6.

4 Fyfe IS, Guion AJ. Skateboard injuries. Injury 1978;10:14951 .

5 Jakobs RA, Keller EL. Skateboard accidents. Pediatrics 1977;59:939-42.

6 Maitra AK. Skateboard injuries. Br f Clin Pract 1979;33: 281-2, 288.

7 Retsky J, Jaffe D, Christoffel K. Skateboarding injuries in children. A second wave. American fournal of Diseases of Children 1991;145:188-92.

8 Smith RG. Skateboard injuries. Can Med Assoc f 1979;121: 510-12.

9 Cassorla A. The ultimate skateboard book. Philadelphia: Running Press, 1988:17.
10 Allum RL. Skateboard injuries; A new epidemic. Injury 1978;10:152-3.

11 Maddox D. Skateboarders zip- and zap-riders once again. Physician and Sports Medicine 1976;4:24-5.

12 Atienza F, Sia C. The hazards of skateboard riding. Pediatrics 1976;57:793.

13 Banas MP, Dalldorf PG, Marquardt JD. Skateboard and in-line skate fractures: a report of one summers' experience. F Orthop Trauma 1992;6:301-5.

14 Hawkins RW, Lyne ED. Skeletal trauma in skateboard injuries. American fournal of Diseases in Children 1978;132:7512.

15 Kemm I. Skateboard injuries. BMF 1978;1:894.

16 Association for the Advancement of Automotive Medicine. The Abbreviated Injury Scale, 1990 Revision. Des Plaines: Association for the Advancement of Automotive Medicine.

17 Christian MS, Khan O. Skateboard injuries: a current appraisal. Br f Sports Med 1980;14:102-4.

18 Hawkins RW, Lyne ED. Skateboard fractures. Am 7 Sports Med 1981;9:99-102.

19 Morgan WJ, Galloway DJ, Patel AR. Prevention of skateboard injuries. Scot Med F 1980;25:39-40.

20 Schieber RA, Branche-Dorsey CM, Ryan GW. Comparison of in-line skating injuries with rollerskating and skateboarding injuries. FAMA 1994;271:1856-8.

21 Tordai P. Rullbrädsolyckor: en frekvens- och skadeanalys. Läkartidningen 1979;76:2781-3.

22 Illingworth CM, Jay A, Noble D, et al. 225 skateboard injuries in children. Clin Pediatr 1978;17:781-9.

23 Brudvik C. Rollerblading and skateboarding injuries in children in Bergen, Norway. Tidsskr Nor Legeforen 2001;121: $19-22$.

24 Carragher AM, Sulaiman SK, Panesar KJS. Scrotoabdominal impalement injury in a skateboard rider. $\mathcal{f}$ Emerg Med 1990;8:419-21.

25 Cass DT, Ross F. Skateboard injuries. Med F Aust 1990;153: $140-4$.

26 Committee on Accident and Poison Prevention. Skateboard Injuries. Pediatrics 1989;83:1070-1.

27 Boyle WE. Skateboard injuries. Pediatrics 1995;95:611-12. 8 Pendergrast RA. Skateboard injuries in children. $f$ Adolesc Health Care 1990;11:408-12.

29 Committee on Accident and Poison Prevention and Committee on Pediatric Aspects of Physical Fitness, Recreation and Sports. Skateboard Policy Statement. Pediatrics 1979;63:924-5.

\section{Take home message}

Skateboarding today is not only a fun sport and a means of transport for young people, but also part of a lifestyle. To reduce injuries associated with the increased use of skateboards, the use of protective gear and supervised skateboard parks is recommended.

\section{Commentary}

Injury is a problem of our time and a reflection of environmental and product factors in current society. Injury causation is related to popular opinion, with a bias towards prejudices between people with different value systems such as different age groups. "Society should prohibit the use of this or that". One of the few standpoints that should be taken by public health officials is the seriousness of the outcome. This is why clinical epidemiological studies are of great importance. They may not be sophisticated in methodology, but they have great potential for informing the public. This study on skateboard injuries is such an example from an informed source. Clinicians meet the patients and can interview those involved. These factual studies are needed for making comparisons of injury patterns in different exposure groups as well as investigating the environment and dangerous products. The next step should be more detailed interviews in order to suggest better skateboard designs and protection for the skateboarders.

L SVANSTROM

Karolinska Institutet, Department of Public Health Sciences,

Division of Social Medicine, Norrbacka, 8th floor, SE-17176 Stockholm, Sweden

leif.svanstrom@phs.ki.se 